\title{
Linking Jasmonic Acid Signaling, Root Exudates, and Rhizosphere Microbiomes
}

\author{
Lilia C. Carvalhais, ${ }^{1}$ Paul G. Dennis, ${ }^{1}$ Dayakar V. Badri, ${ }^{2}$ Brendan N. Kidd, ${ }^{1}$ Jorge M. Vivanco, ${ }^{2}$ and \\ Peer M. Schenk ${ }^{1}$ \\ ${ }^{1}$ School of Agriculture and Food Sciences, The University of Queensland, Brisbane, QLD 4072, Australia; and ${ }^{2}$ Department of \\ Horticulture and Landscape Architecture and Center for Rhizosphere Biology, Colorado State University, Fort Collins, CO \\ 80523, U.S.A.
}

Submitted 16 January 2015. Accepted 22 May 2015.

\begin{abstract}
Jasmonic acid (JA) is an essential hormone in plant development and defense responses in Arabidopsis thaliana. Exogenous treatment with JA has recently been shown to alter root exudate profiles and the composition of root-associated bacterial communities. However, it is currently unknown whether disruptions of the $\mathrm{JA}$ in the rhizosphere affect root exudation profiles and the relative abundance of bacteria and archaea in the rhizosphere. In the present study, two Arabidopsis mutants that are disrupted in different branches of the jasmonate pathway, namely myc 2 and med25, were cultivated in nutrient solution and soil to profile root exudates and bacterial and archaeal communities, respectively. Compared with the wild type, both mutants showed distinct exudation patterns, including lower amounts of asparagine, ornithine, and tryptophan, as well as distinct bacterial and archaeal community composition, as illustrated by an increased abundance of Streptomyces, Bacillus, and Lysinibacillus taxa in the med 25 rhizosphere and an Enterobacteriaceae population in myc2. Alternatively, the Clostridiales population was less abundant in the rhizosphere of both mutants. Similarities between plant genotypes were highly correlated, as determined by operational taxonomic units in the rhizosphere and metabolites in root exudates. This strongly suggests that root exudates play a major role in modulating changes in microbial community composition upon plant defense responses.
\end{abstract}

Jasmonic acid (JA) mediates several developmental processes in plants, such as stamen and pollen maturation, root growth, tuber formation and senescence, as well as interactions with other organisms (Creelman and Mullet 1997; Feys et al. 1994; He et al. 2002; McConn et al. 1997; Penninckx et al. 1998; Thomma et al. 1998). In response to attack by necrotrophic pathogens and herbivorous insects as well as during interaction with beneficial soil microbes, plants activate the JA signaling pathway. This culminates in the production of chemical and physical defenses or induced systemic resistance (ISR) (Ballaré 2011; McConn et al. 1997).

Current address for B. N. Kidd: Commonwealth Scientific and Industrial Research Organization Agriculture Flagship, Centre for Environment and Life Sciences, Perth, Western Australia, Australia.

Corresponding authors: L. Carvalhais; E-mail: 1.carvalhais@uq.edu.au; P. M. Schenk; E-mail: p.schenk@uq.edu.au

*The $\boldsymbol{e}$-Xtra logo stands for "electronic extra" and indicates that four supplementary figures and two supplementary tables are published online.

(c) 2015 The American Phytopathological Society
While the activation of hormone signaling pathways in response to foliar pests and pathogens is comparatively well studied, much less is known about the ability of rhizosphere bacteria and archaea to modulate hormone pathways despite the abundance of microorganisms that live in association with plant roots. During ISR, certain beneficial soil microbes, including the Pseudomonas fluorescens strains WCS417r and CHA0 as well as strains of Serratia marcescens and Bacillus spp., are known to 'prime' JA- and ethylene (ET)associated defense pathways to increase the response time and intensity in the event of an infection by foliar pathogens (Ahn et al. 2007; Knoester et al. 1999; Pieterse et al. 1996; Van der Ent et al. 2009; Zamioudis and Pieterse 2012). WCS417 secretes lowmolecular weight molecules in the apoplast of Arabidopsis roots and suppresses defense responses induced by flagellin (Millet et al. 2010). As a consequence, systemic resistance against a range of pathogens is gained after a transduction signaling cascade has occurred (Van der Ent et al. 2008). Fungal representatives such as Trichoderma spp. and Sebacinales spp. can also induce systemic resistance (Shoresh et al. 2010).

Activation of the JA signaling pathway in Arabidopsis thaliana occurs with the conjugation of JA to the amino acid, L-isoleucine (Ile), to produce the active hormone (3R, 7S)-jasmonoyl-L-isoleucine (JA-Ile). The F-box protein CORONATINE INSENSITIVE1 (COI1) acts as a coreceptor of JA-Ile (Chini et al. 2007; Sheard et al. 2010; Thines et al. 2007; Yan et al. 2009) and, when bound to JA-Ile, COI1 targets jasmonate ZIM domain proteins for their ubiquitin-mediated protein degradation. This leads to the release of transcription factors such as the master regulator MYC2, which can activate or repress JA-associated gene expression (Chini et al. 2007; Katsir et al. 2008; Kazan and Manners 2013).

MYC2 (also referred to as JASMONATE INSENSITIVE 1; At1g25540) differentially regulates two branches of the JA signaling pathway (Dombrecht et al. 2007). On the one hand, MYC2 is a positive regulator for JA-responsive genes that confer resistance to wounding and insect herbivory. On the other hand, MYC2 negatively regulates JA- and ET-responsive genes that are associated with pathogen defense (Anderson et al. 2004; Boter et al. 2004; Dombrecht et al. 2007; Lorenzo et al. 2004). MYC2 has also been shown to play a role in ISR (Pozo et al. 2008; Van der Ent et al. 2009; Zamioudis and Pieterse 2012). The Arabidopsis transcription factors MYB72 and WRKY8 are also needed for the onset of ISR mediated by rhizosphere bacteria and fungi, respectively (Saenz-Mata et al. 2014; Van der Ent et al. 2008).

Upon attack by necrotrophic pathogens, plants produce both JA and ET, leading to a synergistic activation of pathogen defense genes by transcription factors such as ERF1 (ETHYLENE RESPONSE FACTOR1) and ORA59 (OCTADECANOID-RESPONSIVE 
ARABIDOPSIS APETALA2/ERF59). Downstream of the genes encoding for ERF1 and MYC2 is MEDIATOR25 (MED25) (At1g25540), which encodes a subunit of the Mediator complex (Kidd et al. 2009). The Mediator complex acts as a bridge between transcription factors and RNA polymerase II (Kim et al. 1994; Malik and Roeder 2005). MED25 interacts with JA-associated transcription factors such as MYC2, MYC3, and MYC4 as well as the defense-related transcription factors ERF1 and ORA59 (Çevik et al. 2012; Chen et al. 2012; Ou et al. 2011). Consequently, the expression of JA-responsive genes associated with pathogen defense, wounding, and insect herbivory is attenuated in med 25 mutant plants (Kidd et al. 2009).

Plant-microbe interactions in soils are thought to be mediated, at least in part, by the release of organic materials from roots, known collectively as rhizodeposits (Bais et al. 2006; Dennis et al. 2010). Rhizodeposits can be used as substrates by microorganisms or act as signaling compounds (Badri and Vivanco 2009; Carvalhais et al. 2014). A number of factors have been shown to affect the quantity and composition of important fractions of rhizodeposits such as root exudates, including plant species, developmental stage, and nutrition (Aulakh et al. 2001; Carvalhais et al. 2011, 2013b; Gransee and Wittenmayer 2000). The composition of root exudates and their impact on rhizosphere microbes during plant defense responses, however, remains unclear. Previously, we found that treating plants with exogenous methyl jasmonate alters rootassociated bacterial and archaeal community composition (Carvalhais et al. 2013a). In the present study, we address the following questions. i) Do modifications to the JA signaling pathway affect the composition of root exudates and rhizosphere bacterial and archaeal communities? ii) Do changes in root exudate profiles correlate with changes in rhizosphere bacterial and archaeal communities? iii) Are changes in the abundances of particular microbial populations associated with changes in concentration of specific exudates?
To address these questions, we characterized root exudates and rhizosphere bacterial and archaeal communities of the Arabidopsis thaliana mutants myc 2 and med 25 as well as the wild type. Root exudates were profiled using high performance liquid chromatography-mass spectrometry (HPLC-MS) and gas chromatography-mass spectrometry (GC-MS) and rhizosphere bacterial and archaeal communities were characterized using 16S rRNA gene amplicon pyrosequencing. The mutants myc 2 and med 25 were chosen, as these genes differentially regulate distinct branches of the jasmonate pathway. In summary, the $m y c 2$ mutant has increased defense gene expression but an attenuated wound and insect response, whereas the med $25 \mathrm{mu}-$ tant has both the plant defense and herbivory and wound responsive pathways attenuated. The identification of particular changes in the abundance of rhizosphere microbial populations and root exudate profiles associated with these mutants provided deeper insight into the effect of the JA pathway on root-microbial associations. This study provides evidence to suggest that root exudates released in response to changes in JA signaling may influence the relative abundances of bacteria and archaea in the rhizosphere.

\section{RESULTS}

\section{JA signaling-compromised Arabidopsis mutants} display differential root exudate profiles.

To investigate whether basal JA signaling has a marked effect on root exudate profiles in Arabidopsis plants, root exudates were collected from wild-type Col-0 and JA signaling mutants $m y c 2$ and med25, followed by metabolite characterization using GC-MS and HPLC-MS. Based on GC-MS analysis, a lower abundance of allantoic acid, asparagine, 1-deoxy-erythritol, glutamic acid, glycerol-3-galactoside, ornithine, tryptophan, and unknown compound 219507 were detected in root exudates from med 25 relative

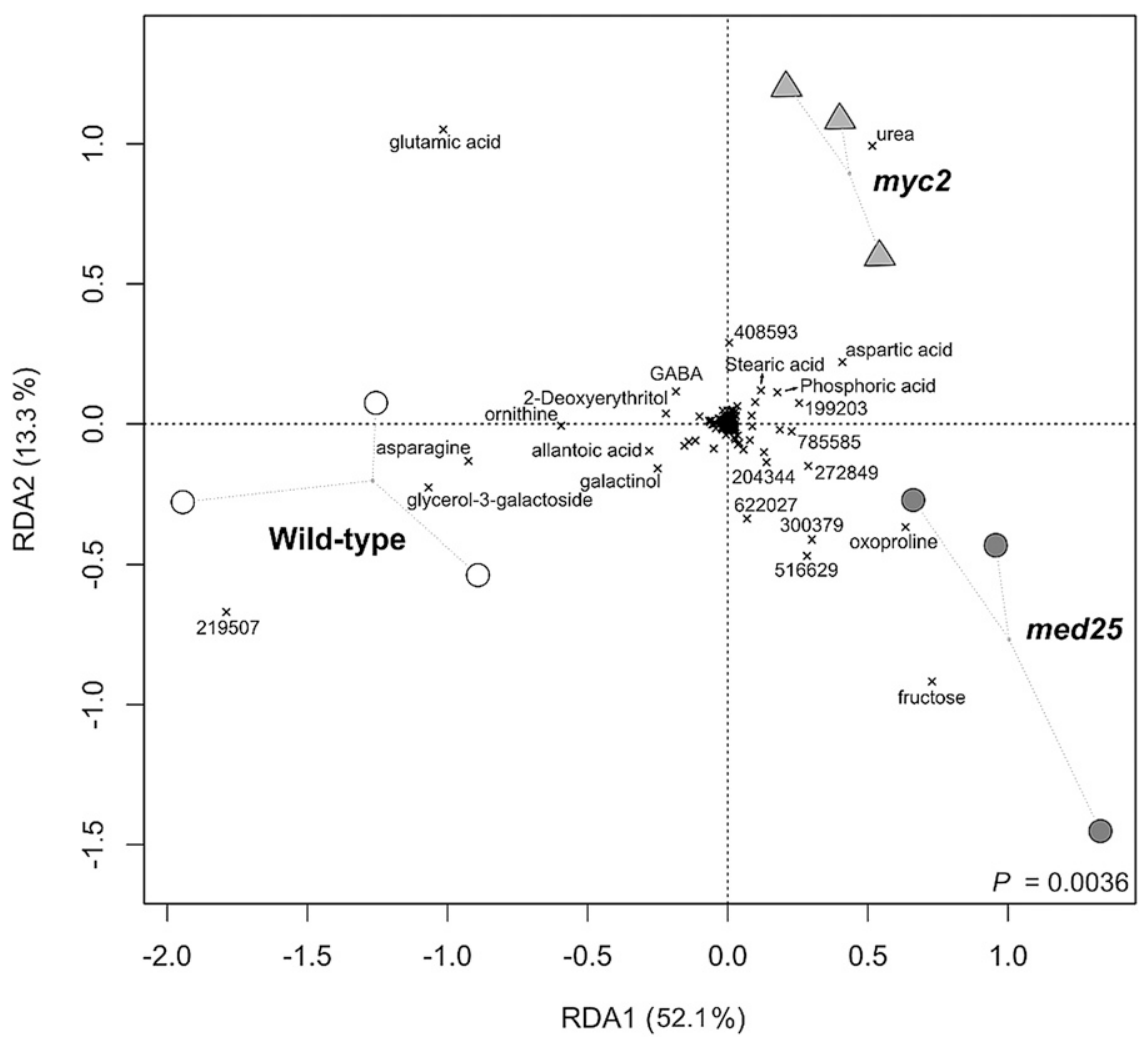

Fig. 1. Redundancy analysis (RDA) ordination summarizing variation in the composition of root exudates collected from wild type and jasmonic acidsignaling mutant rhizospheres detected using gas chromatography-mass spectrometry. Individual exudate components are represented as crosses and those that discriminate between genotypes are labeled. 
to the wild type $(P<0.05)$ (Figs. 1 and 2; Supplementary Table S1). Conversely, aspartic acid, fructose, pyroglutamic acid, phosphoric acid, urea, 2-hydroxy-valeric acid, and unknown compounds 199203 and 300379 were more abundant in med25 root exudates compared with the wild type $(P<0.05)$ (Figs. 1 and 2$)$. For $m y c 2$, allantoic acid, asparagine, 1-deoxy-erythritol, galactinol, glycerol-3-galactoside, ornithine, tryptophan, and unknown compound 219507 were less abundant while aspartic acid, phosphoric acid, urea, and unknown compound 199203 were more abundant than in exudates collected from wild-type plants $(P<0.05)$ (Figs. 1 and 2). The $m y c 2$ mutant has previously been shown to have reduced levels of soluble tryptophan (Dombrecht et al. 2007). Exudation of glutamic acid relative to the wild type was reduced only in med25 plants, while a reduction in the release of galactinol was specific to myc2 $(P<0.05)$ (Figs. 1 and 2). Mutant-specific increases in the release of fructose and pyroglutamic acid were associated with med25 $(P<0.05)$ (Figs. 1 and 2$)$.

Relative to the wild type, HPLC-MS revealed that med 25 and $m y c 2$ released significantly different amounts of 28 and 19 compounds, respectively $(P<0.05)$ (Supplementary Fig. S2). Root exudates of med 25 and $m y c 2$ included 18 and 15 compounds, respectively, that were present at significantly lower concentrations than in the wild type $(P<0.05)$. In contrast, increases in the release of ten and four compounds were observed for $m e d 25$ and $m y c 2$, respectively $(P<0.05)$. The only compound that could be identified from the HPLC analysis was kaempferol 3,7- $\alpha$-L-dirhamnoside $\left(\mathrm{C}_{27} \mathrm{H}_{29} \mathrm{O}_{14}\right)$, which was released by myc 2 at significantly lower rates than by the wild type $(P=0.003)$ (Supplementary Fig. S1). Supporting our results, the expression of a number of flavonoid-associated genes have been shown to be downregulated in the myc 2 mutant (Dombrecht et al. 2007).

\section{Bacterial and archaeal community composition in Arabidopsis rhizosphere soil is distinct from bulk soil and differs significantly between wild-type and $\mathrm{JA}$-signaling mutant plants.}

To ensure that microbial communities that were well adapted to Arabidopsis plants could be characterized, wild type, med25, and $m y c 2$ mutant plants were grown in soil collected from a site in Michigan, U.S.A., where A. thaliana grows naturally. Rhizosphere soil was collected from plants at the eight- to 12-leaf stage, and the bacterial and archaeal diversity was characterized based on pyrosequencing of $16 \mathrm{~S}$ rRNA gene amplicons. At least 1,550 quality-filtered sequences were obtained per sample. These sequences were grouped into operational taxonomic units (OTU), each defined as sequences sharing $97 \%$ similarity. OTU were assigned taxonomy using the GreenGenes 16S rRNA gene database (DeSantis et al. 2006). The most dominant OTU (those present at more than $1 \%$ relative abundance in any sample) were all identified as bacteria except for one archaeal population that was affiliated with the genus Nitrososphaera (Fig. 3).

The composition of bacterial and archaeal communities differed between bulk and rhizosphere soil samples and between wild-type and mutant plant rhizospheres $(P<0.05$, redundancy analysis [RDA]) (Fig. 4). Relative to the wild type, the magnitude of difference in rhizosphere microbial community composition was greater for med 25 than for myc2 (Fig. 4).

Three bacteria belonging to the genus Paenibacillus (OTU 10 to 13 ) were significantly more abundant in med25 than in the wild-type rhizosphere soils (Fig. $3, P<0.05$ ). Similarly, three bacterial groups identified as Streptomyces, Bacillus, and Lysinibacillus taxa (OTU 3, 14, and 15, respectively) were also present at higher abundances in the rhizosphere of med25 compared with wild-type plants (Fig. 3, $P<0.05$ ). In contrast, members of Paenibacillus and Clostridiales (OTU 9 and 16) were less abundant in med25 rhizosphere soil relative to the wild type. The latter was also significantly less abundant in $m y c 2$ soils, although not to the same extent as in med25 (Fig. 3, $P<0.05$ ). Finally, an Enterobacteriaceae population (OTU 17) was more abundant in $m y c 2$ soils than in the wild type (Fig. 3, $P<0.05)$.

\section{Correlation between microbial community composition and root exudate profiles.}

The similarities between genotypes based on microbial community composition and exudate profiles were significantly correlated (Supplementary Fig. S4, $P<0.03$, Procrustes; $P<0.04$, Mantel). Superimposition of the GC-MS and HPLC data on a principal component analysis ordination of bacterial and archaeal OTU by vector fitting revealed 35 and 15 significantly correlated exudate components, respectively (Fig. 5). For GC-MS, 19 of the 35 significantly correlated exudate components were unidentified, while all 14 of the significantly correlated exudate components for HPLC were unidentified.

Changes in the abundances of particular microbial populations were associated with changes in the concentration of specific exudates. For example, a positive correlation was observed between members of order Clostridiales (OTU 16) and the Pseudomonas (OTU 19) population and 1-deoxy-erythritol, glycerol-gulo-heptose, as well as, albeit to a lesser extent,

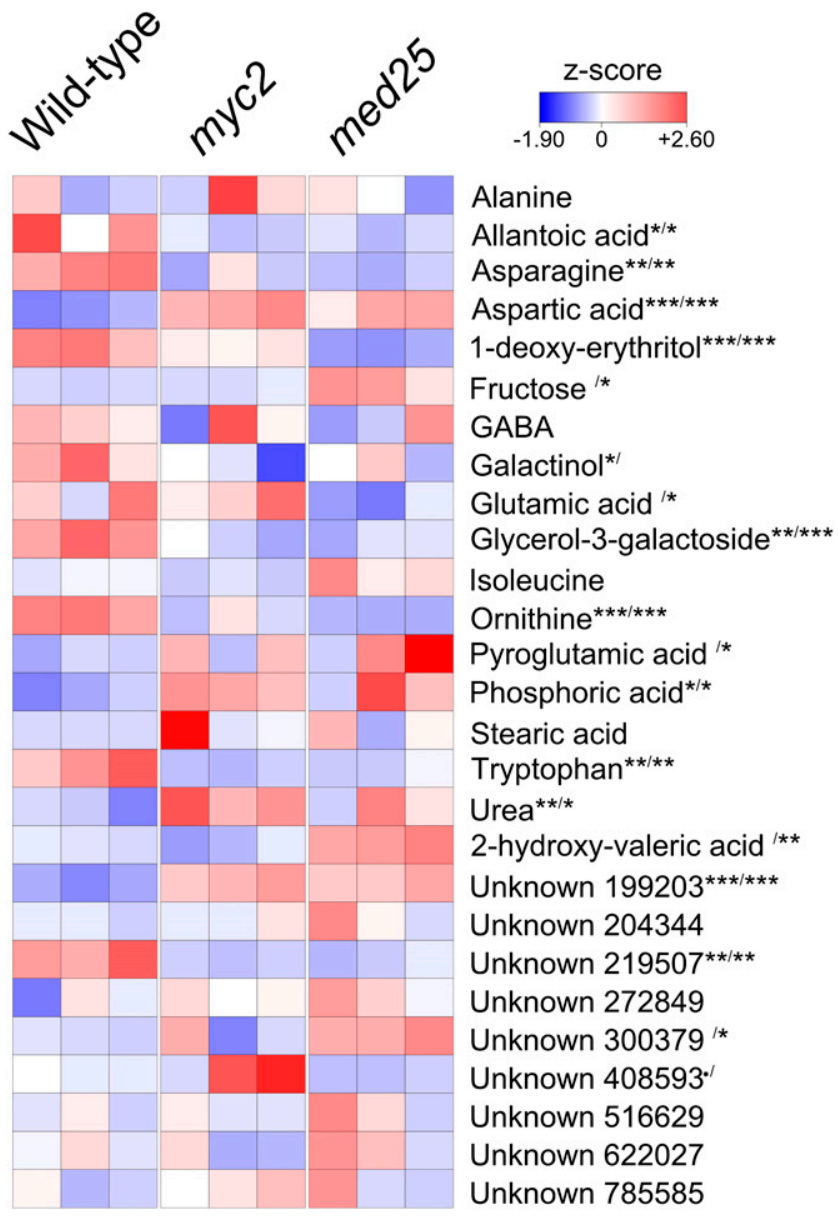

Fig. 2. Heatmap summarizing the abundances of exudate compounds detected by gas chromatography-mass spectrometry that were released by wild type and jasmonic acid-signaling mutant plants. Squares depicted in blocks of three below each genotype represent biological replicates. Codes representing levels of significance for comparisons $m y c 2 \times$ wild type and med $25 \times$ wild type, respectively, were added beside each compound: three asterisks $(* * *)$ represent 0.001 ; two asterisks $(* *), 0.01$; one asterisk $(*)$, 0.05 ; the dot (.), 0.1 ; and no code represents no significant differences. 


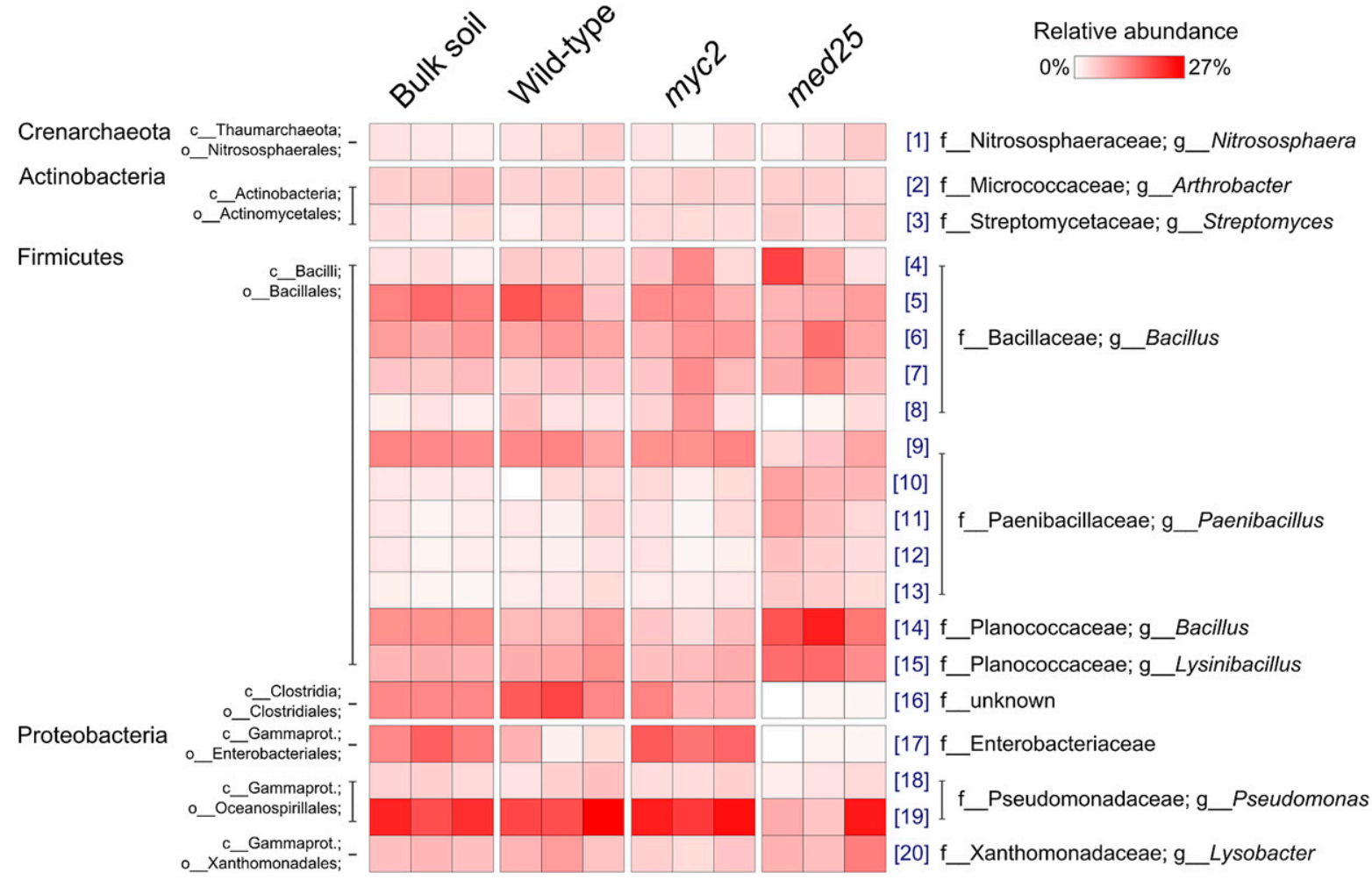

Fig. 3. Heatmap summarizing the relative abundances of operational taxonomic units (OTU) that were present at more than $1 \%$ relative abundance in any sample. The numbers in square brackets indicate OTU numbers and are consistent with those in other figures and text. Squares depicted in blocks of three below each genotype and bulk soil represent biological replicates.

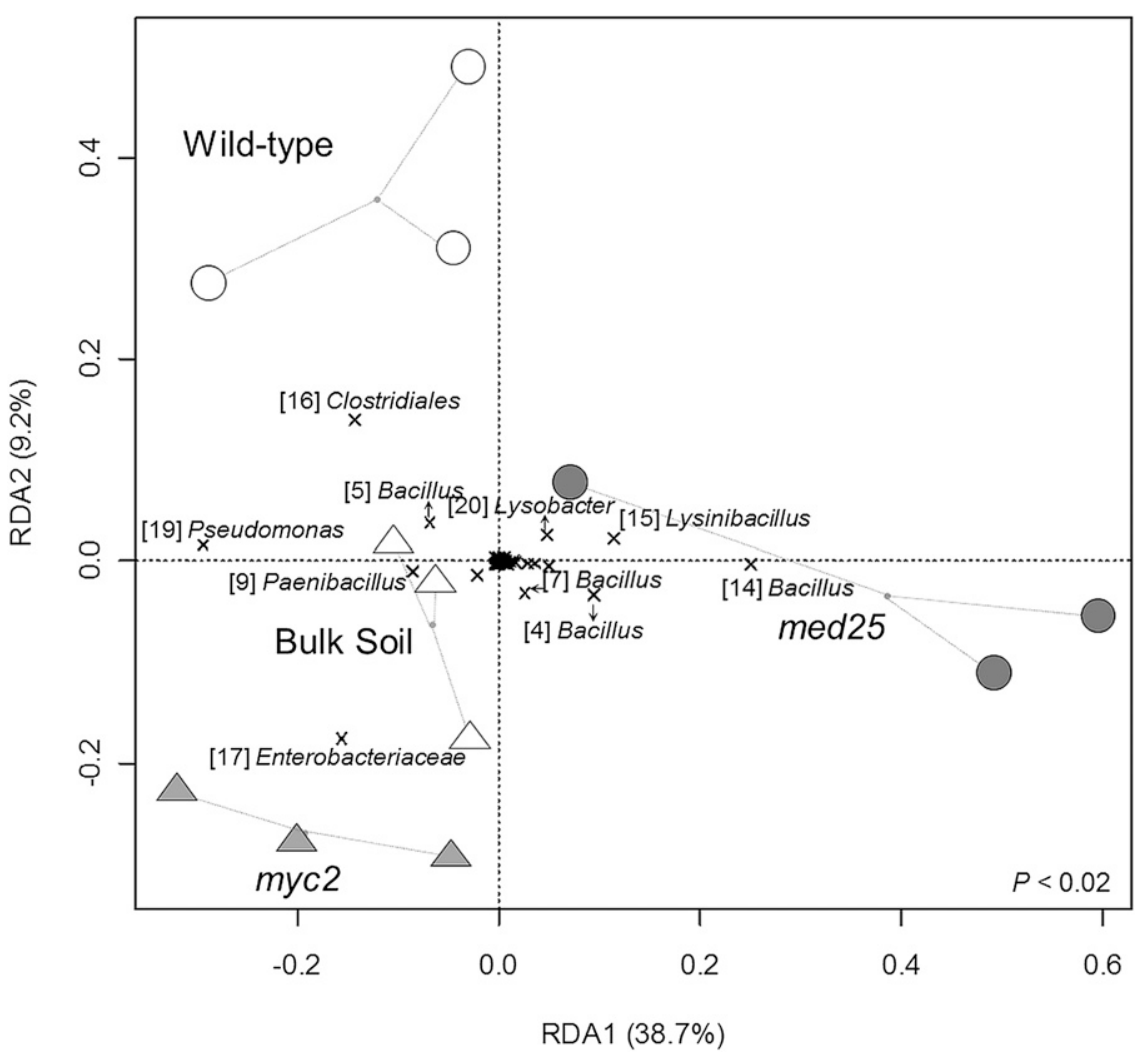

Fig. 4. Redundancy analysis ordination summarizing variation in the composition of bacterial and archaeal communities between bulk and rhizosphere soil samples and between wild-type and mutant rhizospheres. Individual operational taxonomic units (OTU) are represented as crosses. The most discriminating OTU between treatments are numbered in accordance with the heatmap and the main text and include a short taxonomic descriptor. 
histidine and tryptophan, which was released at higher concentrations by the wild type compared with the mutants (Fig. 5). In addition, pronounced increases in myo-inositol delta, mannitol, and benzoic acid were associated with an increase in the abundance of two Bacillus populations (OTU 4 and 7) in the rhizospheres of both mutants relative to the wild type (Fig. 5). Higher concentrations of fructose, glyceric acid, isoleucine, and 2-hydroxy valeric acid in the exudates of med 25 were positively correlated with increases in abundance of two Paenibacillus populations (OTU 10 and 11), a Lysinibacillus sp. (OTU 15), and a Bacillus sp. (OTU 14) (Fig. 5). A higher concentration of tyrosine in the root exudates of med 25 correlated with higher abundances of a Nitrososphaera sp. (OTU 1) and a Lysobacter population (OTU 20).

\section{DISCUSSION}

JA is an essential signaling compound during ISR, which is a process mediated by rhizosphere bacteria that augments and accelerates a plant's capacity to respond to herbivory and pathogen attack (Van der Ent et al. 2009). Previously, we have documented that exogenous activation of the JA defense signaling pathway in Arabidopsis wild-type plants influences rhizosphere bacterial community composition (Carvalhais et al. 2013a). In the present study, we investigated how changes in root exudation upon modulation of the JA signaling pathway influence rhizosphere bacterial and archaeal communities. Our key findings were that modifications to the JA signaling pathways affected the composition of root exudates and rhizosphere bacterial and archaeal communities, and these changes significantly correlated with each other. For instance, we demonstrated that, relative to the wild type, both mutants released lower amounts of asparagine, ornithine, and tryptophan, and med25 released less glutamic acid. Asparagine, glutamic acid, and tryptophan have been reported to be chemotactic to plant-associated bacteria, including Rhizobium leguminosarum, Bacillus subtilis, Bacillus megaterium, Pseudomonas putida, Pseudomonas fluorescens, and Azospirillum brasilense (Gaworzewska and Carlile 1982; Hanlon and Ordal 1994; Scher et al. 1985; Sood 2003; Zheng and Sinclair 1996; Zhulin et al. 1988). Ornithine can be utilized by a wide range of diazotrophs and by the plant growth-promoting bacterium Pseudomonas fluorescens. In addition, ornithine has been shown to contribute to the distinction of soil microbial populations in the presence of spruce seedlings, based on substrate utilization profiles (Jones et al. 2007; Madhaiyan et al. 2010; Park et al. 2005; Shishido and Chanway 1998). It is possible that differences in microbial composition between the wild type and mutants result from either chemotactic responses of some microbial groups toward asparagine and tryptophane, their ability to utilize ornithine, or both. Conversely, fructose was present at higher concentrations in root exudates of med 25 compared with the wild type. This sugar has been shown to be chemotactic toward Bacillus subtilis (Ordal et al. 1979), which may be the reason why a member of genus Bacillus (Planococcaceae) was more abundant in the rhizosphere of med25 (Figs. 3 and 4). The mutant myc2 exuded lower amounts of galactinol compared with the wild type. Galactinol acts as a signal during Pseudomonas chlororaphis O6-mediated ISR against the necrotrophic fungus Corynespora cassiicola (Kim et al. 2008). As previously mentioned, ISR is MYC2-dependent; therefore, the role played by MYC2 during ISR may be related to the regulation of galactinol concentration in

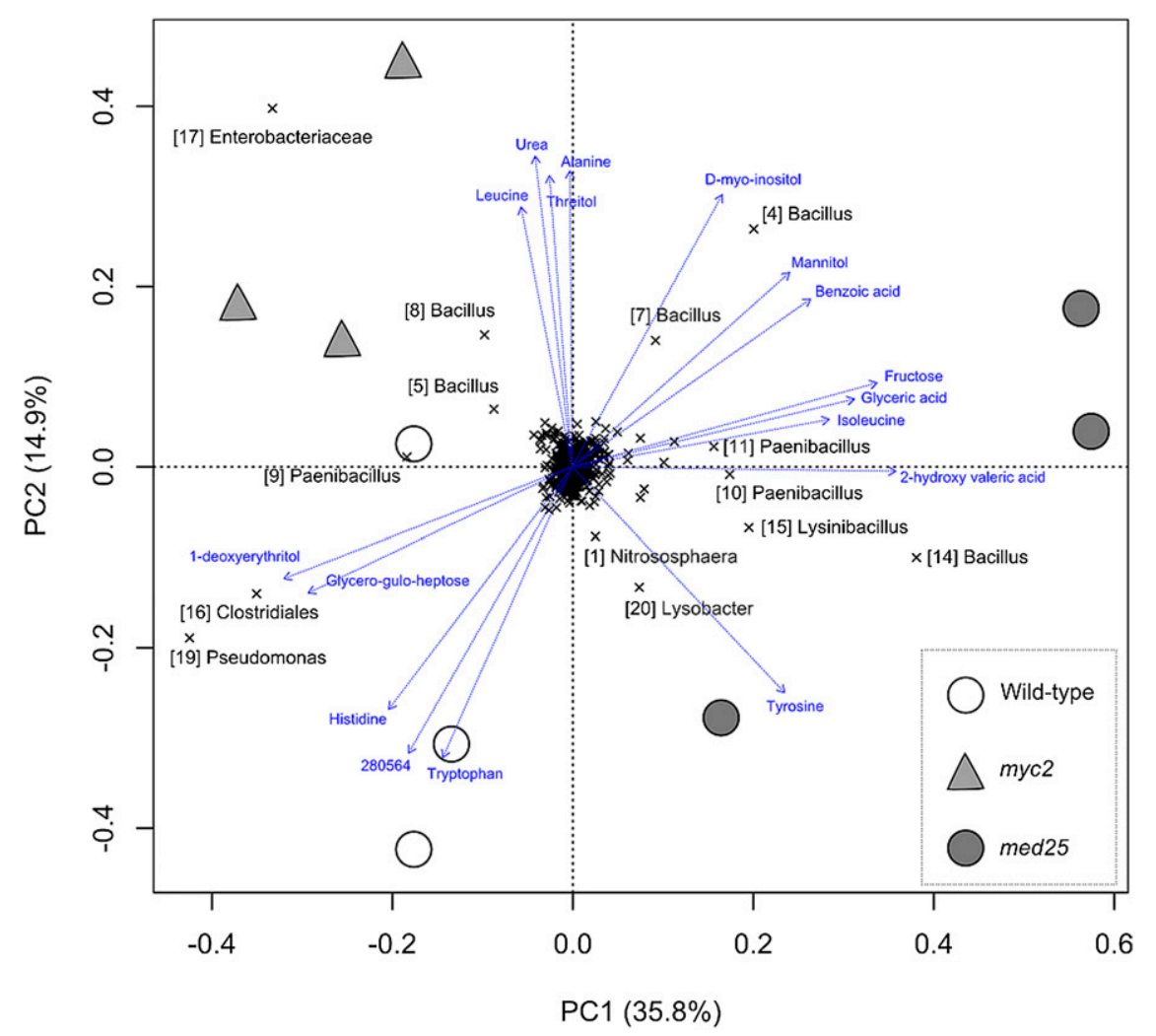

Fig. 5. Principal component analysis ordination summarizing variation in the composition of bacterial and archaeal communities between wild-type and mutant plant rhizospheres with selected exudate components superimposed as fitted vectors. Individual operational taxonomic units (OTU) are represented as crosses. The most discriminating OTU between treatments are numbered in accordance with the heatmap and include a short taxonomic descriptor. The arrows show the magnitude (length of arrow) and correlation (angle of arrow) of exudate components that were significantly correlated with the ordination $(P<0.05$ for identified components and $P<0.001$ for unidentified components). 
root exudates. We provide the first evidence indicating that differences in rhizosphere bacteria and archaea between JA mutants may be influenced by changes in root exudation profiles. It is interesting to note that these events took place without activation of the JA pathway in any of the plant genotypes, which means that all observed differences were detected at basal levels of jasmonate signaling. Much-larger differences may potentially be detected when the JA pathway has been activated. For example, MYC2 has been found to differentially regulate gene expression of approximately $10 \%$ of all Arabidopsis genes when the JA pathway was induced by methyl jasmonate (Dombrecht et al. 2007).

Our results revealed that med 25 selected a more distinct rhizosphere microbial community relative to the wild type than myc2 (Fig. 4). It seems, therefore, that a functional MED25 is needed for shaping the microbial communities in Arabidopsis plants. As previously mentioned, MED25 is required for the expression of JA-responsive genes involved in wounding, insect herbivory, and pathogen defense (Kidd et al. 2009). Although wounding and herbivory are also positively regulated by MYC2, JA/ET-associated defense genes active against pathogens are negatively regulated by this transcription factor and are, therefore, expressed higher in $m y c 2$ than in the wild type in response to pathogen elicitation or hormone treatment (Dombrecht et al. 2007). However, in med25, defense genes and wound responsive genes remain significantly attenuated both under basal conditions and, also, after pathogen or hormone treatment (Kidd et al. 2009).

Our results also provide evidence to suggest that MYC2 positively regulates one or both the synthesis and secretion of kaempferol 3, 7- $\alpha$-L-dirhamnoside, as it was found in lower concentrations in root exudates of $m y c 2$ relative to the wild type. Kaempferol rhamnoside derivatives extracted from Bryophyllum pinnatum have been shown to possess antibacterial, antifungal, and antioxidant activity and, therefore, can affect the relative abundances of certain microbial groups (Carlton et al. 1991; Holler et al. 2012; Tatsimo et al. 2012).

The role of root exudates in recruiting specific microbes during pathogen attack has been suggested in previous studies. For instance, Arabidopsis Col-0 plants have been shown to recruit the biocontrol strain Bacillus subtilis FB17 to colonize roots, when infected by the bacterial leaf pathogen Pseudomonas syringae pv. tomato DC3000 in a gnotobiotic system (Rudrappa et al. 2008). Higher concentrations of malic acid were found in root exudates of Pseudomonas syringae pv. tomato-infected compared with noninfected plants and this organic acid is also a chemoattractant to FB17 (Rudrappa et al. 2008). The higher abundance of aspartate in the root exudates of myc 2 and med 25 may result from insufficient conjugation of indole-3-acetic acid (IAA) to aspartate due to impaired JA signaling. The expression of GH3 genes, which encode IAA-amide synthetases, was shown to be regulated by jasmonate in pea seedlings (Ostrowski and Jakubowska 2013). IAA-amide synthetases are involved in hormonal homeostasis in plants by conjugating excess IAA to amino acids, such as aspartate (Staswick et al. 2005). Similarly, because of defective JA signaling, the mutant med 25 may have exhibited higher fructose concentrations in root exudates relative to the wild type. Lower fructose levels were also found in roots of Amaranthus cruentus after partial defoliation produced either by insect herbivory and mechanical damage, which are processes well-known to be regulated by JA signaling (Castrillón-Arbeláez et al. 2012). Lower concentrations of tryptophan were found in the root exudates of both JA signaling mutants, and this agrees with previous findings that $m y c 2$ has lower levels of soluble tryptophan (Dombrecht et al. 2007). Likewise, a study that investigated the effect of herbivory on maize root metabolome revealed that higher levels of tryptophan were present in fresh root tissue $48 \mathrm{~h}$ after attack by the pest Spodoptera littoralis (Marti et al. 2013). Since JA induces auxin biosynthesis and tryptophan is an IAA precursor (Müller et al. 1998; Sun et al. 2009), lower tryptophan amounts in root exudates of med 25 and $m y c 2$ may result from the downregulation of root tryptophan biosynthesis genes due to the low JA levels.

Various compounds detected by both HPLC and GC-MS analysis could not be identified. As we used ethyl acetate partitioning for prepurification of secondary metabolites, it is possible that some secondary metabolites including phenolics could not solubilize in ethyl acetate. Therefore, trifluorocacetic acid hydrolysis could have been used in one aliquot of root exudates prior to ethyl acetate partitioning of each sample to improve the detection of secondary metabolites.

A major drawback of solution cultures, however, is the alteration of morphological and physiological plant traits compared with plants grown in soil. For instance, in nutrient solution, plants have different root-branching patterns, typically do not develop root hairs, and have no mechanical impedance or radial as well as longitudinal gradients (Jones 1998; Vranova et al. 2013). Other factors, including aeration, plant nutritional status, and interaction with microbes, are quite distinct in nutrient solutions compared with those present in soils (Jones 1998). In addition, when plants are grown under axenic conditions, such as the one in our study, rapid consumption of available $\mathrm{C}$ by microbes does not occur, which creates a gradient of diffusion from root cells to the surrounding environment (Shepherd and Davies 1994). Advantages of analyzing root exudates of plants grown in nutrient solution include the integrity of compounds, the sufficient abundance of exudate material, the lower probability of mechanical damage during handling of plants given the absence of solid particles (Jones 1998; Vranova et al. 2013), and the absence of degradation of compounds by soil microbes. We chose not to grow plants in sterile sand as a solid cultivation medium because positively charged compounds, in particular (e.g., aromatic organic acids), may be underestimated due to adsorption to sand particles during percolation (Vranova et al. 2013). Furthermore, waterlogging of sand is likely to cause solute leakage and irreversible root injury as a consequence of plants undergoing anoxia (Greenway et al. 1992). For the purposes of the present study, we considered the advantages of using nutrient solution to cultivate plants for root exudate collection to outweigh the disadvantages. However, the differences in the two systems must be considered when evaluating the potential relationships among relative abundances of specific bacterial or archaeal populations in soil and the differential exudation of compounds in nutrient solution. Nevertheless, the significant correlations of dissimilarity between genotypes based on community and exudate profiling support roles for MED25 and MYC2 in affecting root exudate release and shaping rootassociated microbial communities, with these roles potentially mechanistically interconnected.

Significant changes in abundances of specific rhizosphere bacterial and archaeal populations among the three investigated genotypes were observed, and the exudate analysis identified compounds secreted by the roots that may influence these changes. Our results suggest that genes associated with the control of defense responses against necrotrophic pathogens and herbivores affect the abundance of rhizosphere populations by modifying root exudate profiles. Nevertheless, the direct effect of altered root exudation profiles in JA-signaling mutants on the rhizosphere microbiome still remains to be elucidated. Thus, further experiments are warranted to demonstrate the ability of root exudates to select microbes, identified based on correlation analyses. A deeper knowledge into the manipulation of soil microbiota by endogenous pathways 
may provide novel breeding strategies to improve sustainable yields of crop plants.

\section{MATERIALS AND METHODS}

Plant growth conditions and root exudates collection.

Plant growth. Soil was collected from the Michigan Extension Station, Benton Harbor, MI, U.S.A. (N42 $05^{\prime}$ 34', W86 21' 19" W, $192 \mathrm{~m}$ above sea level) in March 2011. The soil type was sandy loam, and other characteristics, such as $\mathrm{pH}$ and nutrient content (organic matter, carbon, nitrogen, phosphorus, potassium, zinc, ferrous, manganese, and copper), have been described previously (Sugiyama et al. 2012). Arabidopsis thaliana ecotype Col-0 (wild type) plants and the knock-out mutants myc2 (Dombrecht et al. 2007) and med25 (Kidd et al. 2009) were grown in a controlled environment chamber (Percival Scientific, Boone, IA, U.S.A.) at $24^{\circ} \mathrm{C}$ with a light intensity of $150 \mu \mathrm{mol} \mathrm{m} \mathrm{s}^{-2}$. All plants were harvested at the eight- to 12-leaf stage. Rhizosphere soil (soil closely attached to roots) was collected and stored in Lifeguard soil preservation solution (MO BIO Laboratories, Carlsbad, CA, U.S.A.) at $-20^{\circ} \mathrm{C}$ until samples were processed. Three biological replicates were used per treatment, and each of these replicates was comprised of pooled rhizosphere soil collected from nine or ten plants.

Axenic plant growth conditions and root exudates collection. Arabidopsis seeds were surface-sterilized with commercial bleach $(5 \% \mathrm{vol} / \mathrm{vol} \mathrm{NaClO})$ for $1 \mathrm{~min}$, followed by five washes with sterile distilled water. Seeds were then placed on a solid Murashige and Skoog medium, pH 5.8 (Murashige and Skoog 1962), and were kept in a controlled environment chamber (Percival Scientific) with a light intensity of $150 \mu \mathrm{mol} \mathrm{m} \mathrm{m}^{-2} \mathrm{~s}^{-1}$ at $25^{\circ} \mathrm{C}$, with a photoperiod of $16 \mathrm{~h}$ of light and $8 \mathrm{~h}$ of dark. After 7 days, seedlings were transferred to six-well culture plates (VWR Scientific, Radnor, PA, U.S.A.) and each well was filled with $5 \mathrm{ml}$ of liquid Murashige and Skoog medium (basal salts supplemented with $1 \%$ [wt/vol] sucrose). Plates were incubated on an orbital shaker at $90 \mathrm{rpm}$ and were illuminated under cool-white fluorescent light $\left(45 \mu \mathrm{mol} \mathrm{m} \mathrm{m}^{-2} \mathrm{~s}^{-1}\right)$ with a photoperiod of $16 \mathrm{~h}$ of light and $8 \mathrm{~h}$ of dark at $25^{\circ} \mathrm{C}$. After 18 days, plants were washed with sterile water and were transferred to a new six-well plate containing $5 \mathrm{ml}$ of halfstrength liquid Murashige and Skoog medium without sucrose. Root exudates were then collected 3 days later, when plants achieved the eight- to 12-leaf stage. All roots were fully submerged, while some lower leaves were in partial contact with the nutrient solution. Keeping plants in water for more than $6 \mathrm{~h}$ may lead to overestimation of root exudation due to increased membrane leakiness attributed to leaching of calcium for membrane stabilization (Cakmak and Marschner 1988). However, as all plants (wild type and mutants) were exposed to the same conditions, we assumed that comparisons between treatments are valid. Three biological replicates were used per treatment (mutants $m y c 2$, med25, and wild type), and each biological replicate consisted of exudates pooled from 18 plants.

Root exudate analyses. GC-MS was used to characterize a wide range of primary and secondary metabolites, while HPLC-MS was used to detect nonpolar secondary metabolites, such as phenolics (Badri et al. 2013). The liquid media containing root exudates from 18 plants $(5 \mathrm{ml}$ per plant) were pooled to comprise one biological replicate, which was filtered using nylon filters of pore size $0.45 \mu \mathrm{m}$ (Millipore, Billerica, MA, U.S.A.) to remove root sheathing, broken cells, and root border-like cells. The filtrate was then freeze-dried and, subsequently, dissolved in $5 \mathrm{ml}$ of double-distilled water. The resulting concentrate was partitioned three times with $5 \mathrm{ml}$ of ethyl acetate (Fisher Scientific, Waltham, MA, U.S.A,). The ethyl acetate fractions were then pooled and dried under nitrogen gas. The dried concentrate was then dissolved in $1 \mathrm{ml}$ of absolute methanol (Fisher Scientific) and was analyzed by HPLC-MS.

HPLC-MS. Ethyl acetate fractions partitioned from the root exudates of mutants and wild type were analyzed by HPLC-MS by using gradient elution on a $150 \times 4.6 \mathrm{~mm}$ reverse phase, C18 column (Dionex), with a flow rate of $0.7 \mathrm{ml}$ per minute. The gradient was set up with the methanol:water solvent system: 0 to $3 \mathrm{~min}, 90 \%$ (vol/vol) water and $10 \%$ (vol/vol) methanol; 3 to $43 \mathrm{~min}, 10$ to $90 \%(\mathrm{vol} / \mathrm{vol})$ methanol, 90 to $10 \%(\mathrm{vol} / \mathrm{vol})$ water; 43 to $51 \mathrm{~min}, 90 \%$ (vol/vol) methanol and $10 \%$ (vol/vol) water. The resultant chromatograms were analyzed with the help of a UV-visible photodiode detector at $280 \mathrm{~nm}$ wavelength. The HPLC system was also connected with an MSQ-MS detector system (Thermo Electron Co., Waltham, MA, U.S.A.) to determine the masses of the candidate peaks. The abundance of each peak was determined based on the peak area. One of the peaks showed a retention time of 31.8 and positive ESIMS: $\mathrm{m} / \mathrm{z}$ 579. It was identified as kaempferol 3,7- $\alpha$-L-dirhamnoside $(\mathrm{C} 27 \mathrm{H} 29014)$ by running authentic standard compounds isolated from Arabidopsis root tissues and were then characterized using previously described methods (Badri et al. 2008).

$G C-M S$. Plant growth conditions and root exudates of the mutants and wild type were collected following a method similar to HPLC-MS analysis with a modification. When plants were 18 days old, they were washed gently in sterile distilled water and were transferred to new six-well plates filled with $5 \mathrm{ml}$ of sterile distilled water in each well instead of Murashige and Skoog liquid medium supplemented with $1 \%$ (wt/vol) sucrose. Root exudates were collected in sterile distilled water to prevent the interference of exogenously supplemented salts and sucrose present in the Murashige and Skoog liquid medium for the subsequent GC-MS analyses. GC-MS analyses were performed at the Genome Center Core Services, University of California, Davis to profile the compounds in the root exudates of mutants and wild type. Whole root exudates were subjected to methoximation and trimethylsilylation derivatisation as previously described (Sana et al. 2010). Quantification was determined based on peak height of the unique ion as default. Based on the retention index and mass spectrum, peaks were unambiguously assigned by the BinBase identifier numbers and matched against the Fiehn mass spectral library (Metabolomics Fiehn Lab website). Data were normalized by using 'total metabolite content' as previously described (Fiehn et al. 2008).

Statistical analysis of metabolite data. The quantity of each exudate compound was expressed as a unit of standard deviation above or below the average of all compounds within each sample by performing a $z$ score transformation. Differences in metabolite composition between genotypes were then assessed using RDA. Comparisons of individual exudate compounds and OTU between genotypes were performed using linear regression. Procrustes rotation was used to compare the geometric distribution of the RDA of OTU and metabolite data. The Mantel test was also employed to examine the correlation between the RDA of the OTU and root exudate metabolites. These statistical analyses were implemented using the $\mathrm{R}$ package vegan (Dixon 2003).

\section{Microbial community analysis.}

DNA extraction, polymerase chain reaction (PCR) amplification, sequencing, and data processing and statistical analysis. Total DNA was extracted from soil samples, using the PowerSoil DNA isolation kit according to the manufacturer's instructions (MO BIO Laboratories). The quality of the extracted DNA was assessed on a $1 \%$ agarose gel. Extracted DNA concentrations were determined using a Qubit fluorometer with Quant-iT 
dsDNA BR assay kits (Invitrogen, Waltham, MA, U.S.A.) and were then normalized to $10 \mathrm{ng} \mu \mathrm{l}^{-1}$. Universal $16 \mathrm{~S}$ rRNA genes were amplified by PCR in 50- $\mu \mathrm{l}$ volumes containing $20 \mathrm{ng}$ of DNA, molecular biology grade water, $1 \times \mathrm{MgCL}_{2}$-free $\mathrm{PCR}$ buffer (Invitrogen), $50 \mathrm{nM}$ of each of the dNTPs (Invitrogen), $1.5 \mathrm{mM} \mathrm{MgCl}_{2}$ (Invitrogen), $0.3 \mathrm{mg}$ bovine serum albumin (New England Biolabs, Ipswich, MA, U.S.A.), 0.02 U Taq DNA polymerase (Invitrogen), $8 \mu \mathrm{M}$ each of the primers $803 \mathrm{~F}$ and 1392R modified at the $5^{\prime}$ end to contain the 454 FLX Titanium Lib L adapters B and A, respectively. The reverse primers also contained a 5 to 6 base barcode sequence positioned between the primer sequence and the adapter. A unique barcode was used for each sample. Thermocycling conditions were as follows: $95^{\circ} \mathrm{C}$ for $3 \mathrm{~min}$; then, 30 cycles of $95^{\circ} \mathrm{C}$ for $30 \mathrm{~s}, 55^{\circ} \mathrm{C}$ for $45 \mathrm{~s}, 72^{\circ} \mathrm{C}$ for $90 \mathrm{~s}$; and then, $72^{\circ} \mathrm{C}$ for $10 \mathrm{~min}$. Amplifications were performed using a Veriti 96-well thermocycler (Applied Biosystems, Foster City, CA, U.S.A.). Amplicons were purified using a QIAquick PCR purification kit (Qiagen, Hilden, Germany), were quantified using a Qubit fluorometer with a Quant-iT dsDNA BR assay kit, and then, were normalized to $25 \mathrm{ng} \mathrm{\mu l}^{-1}$ and were pooled for 454 pyrosequencing. Sequencing was performed by the Australian Centre for Ecogenomics at The University of Queensland (Brisbane, Australia).

Sequences were processed as previously described (Dennis et al. 2013a, b, and c). Briefly, sequences were quality filtered and dereplicated using the QIIME script split_libraries.py with the homopolymer filter deactivated (Caporaso et al. 2010) and were then checked for chimeras against the GreenGenes database using UCHIME ver. 3.0.617 (Edgar et al. 2011). Homopolymer errors were corrected using Acacia (Bragg et al. 2012). Sequences were then subjected to the following procedures using QIIME scripts with the default settings: i) sequences were clustered at $97 \%$ similarity, ii) cluster representatives were selected, iii) GreenGenes taxonomy was assigned to the cluster representatives using BLAST, and iv) tables with the abundance of different OTU and their taxonomic assignments in each sample were generated. The number of reads was then normalized to 1,550 per sample by resampling the OTU table. The mean number of OTU (observed richness, $\mathrm{S}_{\mathrm{obs}}$ ) and Simpson's diversity index values (Simpson 1949) corresponding to 1,550 sequences per sample were calculated using QIIME. The values of the $S_{\text {obs }}$, and Simpson's reflect the richness (number of 'species') and evenness (equitability of population abundances within a sample) of microbial communities, respectively. These metrics are core attributes of alpha diversity (within sample diversity). Differences in alpha diversity metrics were investigated using linear regression. Differences in the composition of microbial communities were investigated using redundancy analysis using Hellinger transformed OTU abundances. All analyses were implemented in $\mathrm{R}$ using the package vegan (Dixon 2003).

\section{ACKNOWLEDGMENTS}

We thank the Australian Research Council (DP1094749) for financial support.

\section{LITERATURE CITED}

Ahn, I. P., Lee, S. W., and Suh, S. C. 2007. Rhizobacteria-induced priming in Arabidopsis is dependent on ethylene, jasmonic acid, and NPR1. Mol. Plant-Microbe Interact. 20:759-768.

Anderson, J. P., Badruzsaufari, E., Schenk, P. M., Manners, J. M., Desmond, O. J., Ehlert, C., Maclean, D. J., Ebert, P. R., and Kazan, K. 2004. Antagonistic interaction between abscisic acid and jasmonate-ethylene signaling pathways modulates defense gene expression and disease resistance in Arabidopsis. Plant Cell 16:3460-3479.

Aulakh, M. S., Wassmann, R., Bueno, C., Kreuzwieser, J., and Rennenberg, H. 2001. Characterization of root exudates at different growth stages of ten rice (Oryza sativa L.) cultivars. Plant Biol. 3:139-148.
Badri, D. V., Chaparro, J. M., Zhang, R., Shen, Q., and Vivanco, J. M. 2013. Application of natural blends of phytochemicals derived from the root exudates of Arabidopsis to the soil reveal that phenolic-related compounds predominantly modulate the soil microbiome. J. Biol. Chem. 288:4502-4512.

Badri, D. V., Loyola-Vargas, V. M., Broeckling, C. D., De-la-Pena, C., Jasinski, M., Santelia, D., Martinoia, E., Sumner, L. W., Banta, L. M. Stermitz, F., and Vivanco, J. M. 2008. Altered profile of secondary metabolites in the root exudates of Arabidopsis ATP-binding cassette transporter mutants. Plant Physiol. 146:762-771.

Badri, D. V., and Vivanco, J. M. 2009. Regulation and function of root exudates. Plant Cell Environ. 32:666-681.

Bais, H. P., Weir, T. L., Perry, L. G., Gilroy, S., and Vivanco, J. M. 2006. The role of root exudates in the rhizosphere interactions with plants and other organisms. Annu. Rev. Plant Biol. 57:233-266.

Ballaré, C. L. 2011. Jasmonate-induced defenses: a tale of intelligence, collaborators and rascals. Trends Plant Sci. 16:249-257.

Boter, M., Ruíz-Rivero, O., Abdeen, A., and Prat, S. 2004. Conserved MYC transcription factors play a key role in jasmonate signaling both in tomato and Arabidopsis. Genes Dev. 18:1577-1591.

Bragg, L., Stone, G., Imelfort, M., Hugenholtz, P., and Tyson, G. W. 2012. Fast, accurate error-correction of amplicon pyrosequences using Acacia. Nat. Methods 9:425-426.

Cakmak, I., and Marschner, H. 1988. Increase in membrane permeability and exudation in roots of zinc deficient plants. J. Plant Physiol. 132: 356-361.

Caporaso, J. G., Kuczynski, J., Stombaugh, J., Bittinger, K., Bushman, F. D., Costello, E. K., Fierer, N., Peña, A. G., Goodrich, J. K., Gordon, J. I., Huttley, G. A., Kelley, S. T., Knights, D., Koenig, J. E., Ley, R. E., Lozupone, C. A., McDonald, D., Muegge, B. D., Pirrung, M., Reeder, J., Sevinsky, J. R., Turnbaugh, P. J., Walters, W. A., Widmann, J., Yatsunenko, T., Zaneveld, J., and Knight, R. 2010. QIIME allows analysis of highthroughput community sequencing data. Nat. Methods 7:335-336.

Carlton, R. R., Deans, S. G., Gray, A. I., and Waterman, P. G. 1991 Antifungal activity of a flavonol glycoside from leaves of bog myrtle (Myrica gale). Chemoecology 2:69-71.

Carvalhais, L. C., Dennis, P. G., Badri, D. V., Tyson, G. W., Vivanco, J. M., and Schenk, P. M. 2013a. Activation of the jasmonic acid plant defence pathway alters the composition of rhizosphere bacterial communities. PLOS ONE 8:e56457.

Carvalhais, L. C., Dennis, P. G., Fan, B., Fedoseyenko, D., Kierul, K., Becker, A., von Wiren, N., and Borriss, R. 2013b. Linking plant nutritional status to plant-microbe interactions. PLoS ONE 8:e68555.

Carvalhais, L. C, Dennis, P. G., Fedoseyenko, D., Hajirezaei, M., Borriss, R. and von Wiren, N. 2011. Root exudation of sugars, amino acids, and organic acids by maize as affected by nitrogen, phosphorus, potassium, and iron deficiency. J. Plant Nutr. Soil Sc. 174:3-11.

Carvalhais, L. C., Dennis, P. G., and Schenk, P. M. 2014. Plant defence inducers rapidly influence the diversity of bacterial communities in a potting mix. Appl. Soil Ecol. 84:1-5.

Castrillón-Arbeláez, P. A., Martínez-Gallardo, N., Arnaut, H. A., Tiessen, A., and Délano-Frier, J. P. 2012. Metabolic and enzymatic changes associated with carbon mobilization, utilization and replenishment triggered in grain amaranth (Amaranthus cruentus) in response to partial defoliation by mechanical injury or insect herbivory. BMC Plant Biol. $12: 163$.

Çevik, V., Kidd, B. N., Zhang, P., Hill, C., Kiddle, S., Denby, K. J., Holub, E. B., Cahill, D. M., Manners, J. M., Schenk, P. M., Beynon, J., and Kazan, K. 2012. MEDIATOR25 acts as an integrative hub for the regulation of jasmonate-responsive gene expression in Arabidopsis Plant Physiol. 160:541-555.

Chen. R., Jiang. H., Li. L., Zhai. Q., Qi. L., Zhou. W., Liu. X., Li. H., Zheng. W., Sun. J., and Li, C. 2012. The Arabidopsis mediator subunit MED25 differentially regulates jasmonate and abscisic acid signaling through interacting with the MYC2 and ABI5 transcription factors. Plant Cell 24:2898-2916.

Chini, A., Fonseca, S., Fernández, G., Adie, B., Chico, J. M., Lorenzo, O., García-Casado, G., López-Vidriero, I., Lozano, F. M., Ponce, M. R., Micol, J. L., and Solano, R. 2007. The JAZ family of repressors is the missing link in jasmonate signalling. Nature 448:666-671.

Creelman, R. A., and Mullet, J. E. 1997. Biosynthesis and action of jasmonates in plants. Annu. Rev. Plant Physiol. Plant Mol. Biol. 48: 355-381.

Dennis, P. G., Guo, K., Imelfort, M., Jensen, P., Tyson, G. W., and Rabaey, K. 2013a. Spatial uniformity of microbial diversity in a continuous bioelectrochemical system. Bioresour. Technol. 129:599-605.

Dennis, P. G., Harnisch, F., Yeoh, Y. K., Tyson, G. W., and Rabaey, K. 2013b. Dynamics of cathode-associated microbial communities and 
metabolite profiles in a glycerol-fed bioelectrochemical system. Appl. Environ. Microbiol. 79:4008-4014.

Dennis, P. G., Miller, A. J., and Hirsch, P. R. 2010. Are root exudates more important than other sources of rhizodeposits in structuring rhizosphere bacterial communities? FEMS (Fed. Eur. Microbiol. Soc.) Microbiol. Ecol. 72:313-327.

Dennis, P. G., Seymour, J., Kumbun, K., and Tyson, G. W. 2013c. Diverse populations of lake water bacteria exhibit chemotaxis towards inorganic nutrients. ISME J. 7:1661-1664.

DeSantis, T. Z., Hugenholtz P., Larsen N., Rojas M., Brodie E. L., Keller K. Huber T., Dalevi D., Hu P., Andersen G. L. 2006. Greengenes, a chimerachecked 16S rRNA gene database and workbench compatible with ARB. Appl. Environ. Microbiol. 72:5069-5072.

Dixon, P. 2003. VEGAN, a package of R functions for community ecology J. Veg. Sci. 14:927-930.

Dombrecht, B., Xue, G. P., Sprague, S. J., Kirkegaard, J. A., Ross, J. J., Reid, J. B., Fitt, G. P., Sewelam, N., Schenk, P. M., Manners, J. M., and Kazan, K. 2007. MYC2 differentially modulates diverse jasmonatedependent functions in Arabidopsis. Plant Cell 19:2225-2245.

Edgar, R. C., Haas, B. J., Clemente, J. C., Quince, C., and Knight, R. 2011 UCHIME improves sensitivity and speed of chimera detection. Bioinformatics 27:2194-2200.

Feys, B., Benedetti, C. E., Penfold, C. N., and Turner, J. G. 1994. Arabidopsis mutants selected for resistance to the phytotoxin coronatine are male-sterile, insensitive to methyl jasmonate, and resistant to a bacterial pathogen. Plant Cell 6:751-759.

Fiehn, O., Wohlgemuth, G., Scholz, M., Kind, T., Lee, D. Y., Lu, Y., Moon, S., and Nikolau, B. 2008. Quality control for plant metabolomics: reporting MSI-compliant studies. Plant J. 53:691-704.

Gaworzewska, E. T., and Carlile, M. J. 1982. Positive chemotaxis of Rhizobium leguminosarum and other bacteria towards root exudates from legumes and other plants. J. Gen. Microbiol. 128:1179-1188.

Gransee, A., and Wittenmayer, L. 2000. Qualitative and quantitative analysis of water-soluble root exudates in relation to plant species and development. J. Plant Nutr. Soil Sci. 163:381-385.

Greenway, H., Waters, I., and Newsome, J. 1992. Effects of anoxia on uptake and loss of solutes in roots of wheat. Funct. Plant Biol. 19:233-247.

Hanlon, D. W., and Ordal, G. W. 1994. Cloning and characterization of genes encoding methyl-accepting chemotaxis proteins in Bacillus subtilis. J. Biol. Chem. 269:14038-14046.

He, Y., Fukushige, H., Hildebrand, D. F., and Gan, S. 2002. Evidence supporting a role of jasmonic acid in Arabidopsis leaf senescence. Plant Physiol. 128:876-884.

Holler, J. G., Christensen, S. B., Slotved, H. C., Rasmussen, H. B., Gúzman, A. Olsen, C. E., Petersen, B., and Mølgaard, P. 2012. Novel inhibitory activity of the Staphylococcus aureus NorA efflux pump by a kaempferol rhamnoside isolated from Persea lingue Nees. J. Antimicrob. Chemother. 67:1138-1144.

Jones, D. L. 1998. Organic acids in the rhizosphere-A critical review. Plant Soil 205:25-44

Jones, J., Studholme, D. J., Knight, C. G., and Preston, G. M. 2007. Integrated bioinformatic and phenotypic analysis of RpoN-dependent traits in the plant growth-promoting bacterium Pseudomonas fluorescens SBW25. Environ. Microbiol. 9:3046-3064.

Katsir, L., Schilmiller, A. L., Staswick, P. E., He, S. Y., and Howe, G. A. 2008 COI1 is a critical component of a receptor for jasmonate and the bacterial virulence factor coronatine. Proc. Natl. Acad. Sci. U.S.A. 105:7100-7105.

Kazan, K., and Manners, J. M. 2013. MYC2: The master in action. Mol Plant 6:686-703.

Kidd, B. N., Edgar, C. I., Kumar, K. K., Aitken, E. A., Schenk, P. M. Manners, J. M., and Kazan, K. 2009. The Mediator complex subunit PFT1 is a key regulator of jasmonate-dependent defense in Arabidopsis. Plant Cell 21:2237-2252.

Kim, M. S., Cho, S. M., Kang, E. Y., Im, Y. J., Hwangbo, H., Kim, Y. C. Ryu, C.-M., Yang, K. Y., Chung, G. C., and Cho, B. H. 2008. Galactinol is a signaling component of the induced systemic resistance caused by Pseudomonas chlororaphis O6 root colonization. Mol. Plant-Microbe Interact. 21:1643-1653.

Kim, Y. J., Björklund, S., Li, Y., Sayre, M. H., and Kornberg, R. D. 1994. A multiprotein mediator of transcriptional activation and its interaction with the C-terminal repeat domain of RNA polymerase II. Cell 77:599-608.

Knoester, M., Pieterse, C. M. J., Bol, J. F., and Van Loon, L. C. 1999. Systemic resistance in Arabidopsis induced by rhizobacteria requires ethylene-dependent signaling at the site of application. Mol. PlantMicrobe Interact. 12:720-727.

Lorenzo, O., Chico, J. M., Sánchez-Serrano, J. J., and Solano, R. 2004. JASMONATE-INSENSITIVE1 encodes a MYC transcription factor essential to discriminate between different jasmonate-regulated defense responses in Arabidopsis. Plant Cell 16:1938-1950.
Madhaiyan, M., Poonguzhali, S., Lee, J.-S., Saravanan, V. S., Lee, K.-C., and Santhanakrishnan, P. 2010. Enterobacter arachidis sp. nov., a plantgrowth-promoting diazotrophic bacterium isolated from rhizosphere soil of groundnut. Int. J. Syst. Evol. Microbiol. 60:1559-1564.

Malik, S., and Roeder, R. G. 2005. Dynamic regulation of pol II transcription by the mammalian Mediator complex. Trends Biochem. Sci. 30:256-263.

Marti, G., Erb, M., Boccard, J., Glauser, G., Doyen, G. R., Villard, N., Robert, C. A., Turlings, T. C., Rudaz, S., and Wolfender, J.-L. 2013. Metabolomics reveals herbivore-induced metabolites of resistance and susceptibility in maize leaves and roots. Plant Cell Environ. 36:621-639.

McConn, M., Creelman, R. A., Bell, E., Mullet, J. E., and Browse, J. 1997. Jasmonate is essential for insect defense in Arabidopsis. Proc. Natl Acad. Sci. U.S.A. 94:5473-5477

Millet, Y. A., Danna, C. H., Clay, N. K., Songnuan, W., Simon, M. D. Werck-Reichhart, D., and Ausubel, F. M. 2010. Innate immune responses activated in Arabidopsis roots by microbe-associated molecular patterns. Plant Cell 22:973-990.

Müller, A., Hillebrand, H., and Weiler, E. W. 1998. Indole-3-acetic acid is synthesized from L-tryptophan in roots of Arabidopsis thaliana. Planta 206:362-369

Murashige, T., and Skoog, F. 1962. A revised medium for rapid growth and bio assays with tobacco tissue cultures. Physiol. Plant. 15:473-497.

Ordal, G. W., Villani, D. P., and Rosendahl, M. S. 1979. Chemotaxis towards sugars by Bacillus subtilis. J. Gen. Microbiol. 115:167-172.

Ostrowski, M., and Jakubowska, A. 2013. GH3 expression and IAA-amide synthetase activity in pea (Pisum sativum L.) seedlings are regulated by light, plant hormones and auxinic herbicides. J. Plant Physiol. 170:361-368

Ou, B., Yin, K. Q., Liu, S. N., Yang, Y., Gu, T., Wing Hui, J. M., Zhang, L., Miao, J., Kondou, Y., Matsui, M., Gu, H. Y., and Qu, L. J. 2011. A high-throughput screening system for Arabidopsis transcription factors and its application to Med25-dependent transcriptional regulation. Mol. Plant 4:546-555.

Park, M., Kim, C., Yang, J., Lee, H., Shin, W., Kim, S., and Sa, T. 2005. Isolation and characterization of diazotrophic growth promoting bacteria from rhizosphere of agricultural crops of Korea. Microbiol. Res. 160:127-133.

Penninckx, I. A. M. A., Thomma, B. P. H. J., Buchala, A., Métraux, J. P., and Broekaert, W. F. 1998. Concomitant activation of jasmonate and ethylene response pathways is required for induction of a plant defensin gene in Arabidopsis. Plant Cell 10:2103-2113.

Pieterse, C. M., van Wees, S. C., Hoffland, E., van Pelt, J. A., and van Loon, L. C. 1996. Systemic resistance in Arabidopsis induced by biocontro bacteria is independent of salicylic acid accumulation and pathogenesisrelated gene expression. Plant Cell 8:1225-1237.

Pozo, M. J., Van Der Ent, S., Van Loon, L. C., and Pieterse, C. M. J. 2008. Transcription factor MYC2 is involved in priming for enhanced defense during rhizobacteria-induced systemic resistance in Arabidopsis thaliana. New Phytol. 180:511-523.

Rudrappa, T., Czymmek, K. J., Paré, P. W., and Bais, H. P. 2008. Rootsecreted malic acid recruits beneficial soil bacteria. Plant Physiol. 148 1547-1556.

Saenz-Mata, J., Salazar-Badillo, F. B., and Jimenez-Bremont, J. F. 2014 Transcriptional regulation of Arabidopsis thaliana WRKY genes under interaction with beneficial fungus Trichoderma atroviride. Acta Physiol Plant. 36:1085-1093.

Sana, T. R., Fischer, S., Wohlgemuth, G., Katrekar, A., Jung, K. H., Ronald, P. C., and Fiehn, O. 2010. Metabolomic and transcriptomic analysis of the rice response to the bacterial blight pathogen Xanthomonas oryzae pv. oryzae. Metabolomics 6:451-465.

Scher, F., Kloepper, J., and Singleton, C. 1985. Chemotaxis of fluorescent Pseudomonas spp. to soybean seed exudates in vitro and in soil. Can J. Microbiol. 31:570-574.

Sheard, L. B., Tan, X., Mao, H., Withers, J., Ben-Nissan, G., Hinds, T. R., Kobayashi, Y., Hsu, F. F., Sharon, M., Browse, J., He, S. Y., Rizo, J., Howe, G. A., and Zheng, N. 2010. Jasmonate perception by inositolphosphate-potentiated COI1-JAZ co-receptor. Nature 468:400-405.

Shepherd, T., and Davies, H. V. 1994. Patterns of short-term amino-acid accumulation and loss in the root-zone of liquid-cultured forage rape (Brassica napus L). Plant Soil 158:99-109.

Shishido, M., and Chanway, C. 1998. Forest soil community responses to plant growth-promoting rhizobacteria and spruce seedlings. Biol. Fertil. Soils 26:179-186.

Shoresh, M., Harman, G. E., and Mastouri, F. 2010. Induced systemic resistance and plants responses to fungal biocontrol agents. Annu. Rev. Phytopathol. 48:21-43.

Simpson, E. H. 1949. Measurement of species diversity. Nature 163:688.

Sood, S. G. 2003. Chemotactic response of plant-growth-promoting bacteria towards roots of vesicular-arbuscular mycorrhizal tomato plants. FEMS (Fed. Eur. Microbiol. Soc.) Microbiol. Ecol. 45-219-227. 
Staswick, P. E., Serban, B., Rowe, M., Tiryaki, I., Maldonado, M. T., Maldonado, M. C., and Suza, W. 2005. Characterization of an Arabidopsis enzyme family that conjugates amino acids to indole-3-acetic acid. Plant Cell 17:616-627.

Sugiyama, A., Bakker, M. G., Badri, D. V., Manter, D. K., and Vivanco, J. M 2012. Relationships between Arabidopsis genotype-specific biomass accumulation and associated soil microbial communities. Botany 91:123-126.

Sun, J., Xu, Y., Ye, S., Jiang, H., Chen, Q., Liu, F., Zhou, W., Chen, R., Li, X., Tietz, O., Wu, X., Cohen, J. D., Palme, K., and Li, C. 2009. Arabidopsis ASA1 is important for jasmonate-mediated regulation of auxin biosynthesis and transport during lateral root formation. Plant Cell 21:1495-1511.

Tatsimo, S. J., Tamokou, J. d. D., Havyarimana, L., Csupor, D., Forgo, P., Hohmann, J., Kuiate, J. R., and Tane, P. 2012. Antimicrobial and antioxidant activity of kaempferol rhamnoside derivatives from Bryophyllum pinnatum. BMC Res. Notes 5:158.

Thines, B., Katsir, L., Melotto, M., Niu, Y., Mandaokar, A., Liu, G., Nomura, K. He, S. Y., Howe, G. A., and Browse, J. 2007. JAZ repressor proteins are targets of the SCF(COI1) complex during jasmonate signalling. Nature 448:661-665.

Thomma, B. P., Eggermont, K., Penninckx, I. A., Mauch-Mani, B., Vogelsang, R., Cammue, B. P., and Broekaert, W. F. 1998. Separate jasmonate-dependent and salicylate-dependent defense-response pathways in Arabidopsis are essential for resistance to distinct microbial pathogens. Proc. Natl. Acad. Sci. U.S.A. 95:15107-15111.

Van der Ent, S., Van Wees, S. C. M., and Pieterse, C. M. J. 2009. Jasmonate signaling in plant interactions with resistance-inducing beneficial microbes. Phytochemistry 70:1581-1588.
Van der Ent, S., Verhagen, B. W. M., Van Doorn, R., Bakker, D., Verlaan, M. G., Pel, M. J. C., Joosten, R. G., Proveniers, M. C. G., Van Loon, L. C., Ton, J., and Pieterse, C. M. J. 2008. MYB72 is required in early signaling steps of rhizobacteria-induced systemic resistance in Arabidopsis. Plant Physiol. 146:1293-1304.

Vranova, V., Rejsek, K., Skene, K. R., Janous, D., and Formanek, P. 2013. Methods of collection of plant root exudates in relation to plant metabolism and purpose: A review. J. Plant Nutr. Soil Sc. 176:175-199.

Yan, J., Zhang, C., Gu, M., Bai, Z., Zhang, W., Qi, T., Cheng, Z., Peng, W., Luo, H., Nan, F., Wang, Z., and Xie, D. 2009. The Arabidopsis CORONATINE INSENSITIVE1 protein is a jasmonate receptor. Plant Cell 21:2220-2236.

Zamioudis, C., and Pieterse, C. M. J. 2012. Modulation of host immunity by beneficial microbes. Mol. Plant-Microbe Interact. 25:139-150.

Zheng, X., and Sinclair, J. 1996. Chemotactic response of Bacillus megateriumstrain B153-2-2 to soybean root and seed exudates. Physiol. Mol. Plant Pathol. 48:21-35.

Zhulin, I., Tretyakova, S., and Ignatov, V. 1988. Chemotaxis of Azospirillum brasilense towards compounds typical of plant root exudates. Folia Microbiol. (Praha) 33:277-280.

AUTHOR-RECOMMENDED INTERNET RESOURCE

University of California, Davis Metabolomics Fiehn Lab website: http://fiehnlab.ucdavis.edu/Metabolite-Library-2007 